\title{
Bronchitis in men employed in the coke industry
}

\author{
D. D. WALKER, R. M. ARCHIBALD, and M. D. ATTFIELD \\ Institute of Occupational Medicine, Edinburgh and National Coal Board Medical Service. \\ Hobart House, London
}

\begin{abstract}
Walker, D. D., Archibald, R. M., and Attfield, M. D. (1971). Brit. J. industr. Med., 28, 358-363. Bronchitis in men employed in the coke industry. An epidemiological survey to determine the prevalence of bronchitis in men employed at two of the National Coal Board's coking plants is described. Eight hundred and eighty-one men (91\%) of the total working population were examined.

A strong association was found between bronchitis prevalence and cigarette smoking $(P<0.001)$. In addition, men who smoked and who were exposed to high temperatures, dust, and fumes in the environment of the coke-ovens had more bronchitis than men who worked elsewhere in the cokeworks $(P<0.02)$.

Both the presence of bronchitis and employment in the environment of the coke-ovens had significant and independent effects on ventilatory capacity. The combination of cigarette smoking and previous employment in a dusty industry also had a significant effect on ventilatory capacity.

The investigation suggests that cigarette smoking, and the combination of smoking and pollution from the coke-ovens and previous occupation, appear to be important factors in the aetiology of bronchitis and reduced ventilatory capacity in men employed in the coke manufacturing industry.
\end{abstract}

Of the many factors which may be associated with the development of bronchitis, perhaps the two most important are smoking and atmospheric pollution. There is convincing evidence to show that chronic respiratory disease is more common among smokers than non-smokers (Doll and Hill, 1956; Royal College of Physicians of London, 1962; U.S. Public Health Service, 1964), while atmospheric pollution has been shown to be an important factor which affects bronchitis mortality (Pemberton and Goldberg, 1954; Stocks, 1959; Daly, 1959; Reid, 1964) and the clinical state of bronchitic patients (Lawther, 1967).

The importance of atmospheric pollution at the place of work has been emphasized by Pemberton (1968), who reported a higher mortality from chronic bronchitis among men employed in dusty occupa- tions, such as the coal and steel industries, compared with men employed in non-dusty occupations. Epidemiological field surveys carried out by several workers in recent years (Higgins, Oldham, Cochrane, and Gilson, 1956; Sluis-Cremer, Walters and Sichel, 1967; Kandus, 1968; Lowe, 1968) have also demonstrated the effect of occupation on the incidence of bronchitis symptoms. In a survey on chronic respiratory disease in an industrial town in England, Higgins, Cochrane, Gilson, and Wood (1959) found, in addition to a higher prevalence of respiratory symptoms among miners and ex-miners, that respiratory symptoms occurred more frequently in men exposed to chemical fumes in the course of their work compared with men who had worked only in occupations free from dust or fumes.

However, the role of occupation in the aetiology 
of chronic bronchitis remains uncertain, and the Medical Research Council, in a report to the Ministry of Pensions and National Insurance (1966), concluded on the evidence available that intensity of dust exposure did not appear to be a very significant factor in determining the prevalence of bronchitis in coalminers. Nevertheless, the Council continues to keep the subject under review.

The purpose of the investigation described here was to investigate the prevalence of bronchitis in an industrial population of cokeworkers. It was also decided to examine the possibility that men who worked in the environment of the coke-ovens, where they were regularly exposed to high temperatures, dust, and fumes, might have more bronchitis and a lower ventilatory capacity compared with men who worked elsewhere in the cokeworks. In addition, the presence of a large number of ex-coalminers in the population made it possible to examine the effect of previous employment in a dusty occupation on bronchitis prevalence and ventilatory capacity.

\section{Methods}

The surveys, carried out by one of the National Coal Board's Pneumoconiosis Field Research teams, took place at two cokeworks, one in County Durham and one in Yorkshire. Complete data were obtained for $881(91 \%)$ of the 968 men in the working population. The observations recorded may be summarized briefly as follows:

1. Occupational histories were obtained for all men in order

(a) to identify any past occupations which might have contributed to the development of bronchitis. Such work was termed noxious employment, and men who had worked for more than one year in them were categorized 'dusty'. Almost all these men had previously worked in the coalmining industry. Men with no past history of noxious employment were categorized as 'non-dusty' men;

(b) to determine how long each man had spent in the various occupational groups within the cokeworks so that the population could be divided into two broad groups, ovensmen and other cokeworkers. Ovensmen were defined as men who had worked at any time in one of the jobs in the environment of the coke-ovens (Appendix I) for at least one year, the remainder being described as other cokeworkers.

2. A short questionnaire on respiratory symptoms and smoking habits was completed for each man. On the basis of the answers obtained, each subject was assessed as having or not having bronchitis. This was defined as persistent cough and phlegm for at least three months in the year.

3. Measurements of weight and sitting and standing heights were recorded for each subject.

4. Lung function was tested; the index used in the investigation was the forced expiratory volume $\left(\mathrm{FEV}_{\mathbf{1 . 0}}\right)$ estimated by means of a modified Gaensler spirometer. Four readings were taken, the first of which was discarded, and a mean result was derived from the second, third, and fourth.

5. The examination of each man was completed by taking a $14 \times 14$ in postero-anterior chest $x$-ray to establish the presence of pneumoconiosis, lung cancer or other abnormality.

\section{Results}

In view of the similarity between the findings at the two cokeworks the data were combined.

The overall prevalence of bronchitis in the population was $19 \cdot 2 \%$ (Table 1 ).

The prevalence of bronchitis increased with age and the highest prevalence of $29.3 \%$ occurred in the oldest age group.

\section{Effect on prevalence of bronchitis}

Occupational group and previous industrial experience The prevalence of bronchitis among ovensmen and other cokeworkers is shown in Table 2. Ovensmen had more bronchitis than other cokeworkers, both men without a past history of noxious employment $(18.8 \%$ compared with $11.3 \%)$ and men with such a past history $(27.5 \%$ compared with $20.1 \%)$. Men who worked previously in a noxious occupation had more bronchitis than men without such an occupational history. Thus, the prevalence of bronchitis was higher among 'dusty' ovensmen $(27.5 \%)$ than among 'non-dusty' ovensmen ( $18.8 \%$ ) while among

TABLE 1

Bronchitis AND Age (All Workers)

\begin{tabular}{|c|c|c|c|c|c|c|c|c|c|c|c|c|c|}
\hline & & \multicolumn{12}{|c|}{ Age $(y r)$} \\
\hline & & \multicolumn{2}{|c|}{$15-24$} & \multicolumn{2}{|c|}{$25-34$} & \multicolumn{2}{|c|}{$35-44$} & \multicolumn{2}{|c|}{$45-54$} & \multicolumn{2}{|c|}{$55-64$} & \multicolumn{2}{|c|}{ All ages } \\
\hline & & No. & $\%$ & No. & $\%$ & No. & $\%$ & No. & $\%$ & No. & $\%$ & No. & $\%$ \\
\hline $\begin{array}{l}\text { No bronchitis .. } \\
\text { Bronchitis }\end{array}$ & $\begin{array}{l}\ldots \\
\ldots\end{array}$ & $\begin{array}{r}51 \\
2\end{array}$ & $\begin{array}{r}96 \cdot 2 \\
3.8\end{array}$ & $\begin{array}{r}119 \\
17\end{array}$ & $\begin{array}{l}87 \cdot 5 \\
12 \cdot 5\end{array}$ & $\begin{array}{r}184 \\
30\end{array}$ & $\begin{array}{l}86 \cdot 0 \\
14 \cdot 0\end{array}$ & $\begin{array}{r}206 \\
57\end{array}$ & $\begin{array}{l}78 \cdot 3 \\
21 \cdot 7\end{array}$ & $\begin{array}{r}152 \\
63\end{array}$ & $\begin{array}{l}70 \cdot 7 \\
29 \cdot 3\end{array}$ & $\begin{array}{l}712 \\
169\end{array}$ & $\begin{array}{l}80 \cdot 8 \\
19 \cdot 2\end{array}$ \\
\hline Total & .. & 53 & $100 \cdot 0$ & 136 & $100 \cdot 0$ & 214 & $100 \cdot 0$ & 263 & $100 \cdot 0$ & 215 & $100 \cdot 0$ & 881 & $100 \cdot 0$ \\
\hline
\end{tabular}


TABLE 2

BroNCHITIS AND OCCUPATIONAL GROUP

\begin{tabular}{|c|c|c|c|c|c|c|c|c|c|c|c|c|c|c|}
\hline & & & & & \multicolumn{2}{|c|}{$\begin{array}{l}\text { Ovensmen } \\
\text { non-dusty }\end{array}$} & \multicolumn{2}{|c|}{$\begin{array}{c}\text { Ovensmen } \\
\text { dusty }\end{array}$} & \multicolumn{2}{|c|}{$\begin{array}{c}\text { Other } \\
\text { cokeworkers } \\
\text { non-dusty }\end{array}$} & \multicolumn{2}{|c|}{$\begin{array}{c}\text { Other } \\
\text { cokeworkers } \\
\text { dusty }\end{array}$} & \multicolumn{2}{|c|}{ Total } \\
\hline & & & & & No. & $\%$ & No. & $\%$ & No. & $\%$ & No. & $\%$ & No. & $\%$ \\
\hline $\begin{array}{l}\text { No bronchitis } \\
\text { Bronchitis .. }\end{array}$ & $\begin{array}{l}\cdots \\
\cdots\end{array}$ & $\begin{array}{l}\cdots \\
\cdots\end{array}$ & $\begin{array}{l}\cdots \\
\cdots\end{array}$ & $\begin{array}{l}\cdots \\
\cdots\end{array}$ & $\begin{array}{r}112 \\
26\end{array}$ & $\begin{array}{l}81 \cdot 2 \\
18 \cdot 8\end{array}$ & $\begin{array}{r}142 \\
54\end{array}$ & $\begin{array}{l}72 \cdot 5 \\
27 \cdot 5\end{array}$ & $\begin{array}{r}212 \\
27\end{array}$ & $\begin{array}{l}88 \cdot 7 \\
11 \cdot 3\end{array}$ & $\begin{array}{r}246 \\
62\end{array}$ & $\begin{array}{l}79 \cdot 9 \\
20 \cdot 1\end{array}$ & $\begin{array}{l}712 \\
169\end{array}$ & $\begin{array}{l}80 \cdot 8 \\
19 \cdot 2\end{array}$ \\
\hline Total & . & $\ldots$ & . & . & 138 & $100 \cdot 0$ & 196 & $100 \cdot 0$ & 239 & $100 \cdot 0$ & 308 & $100 \cdot 0$ & 881 & $100 \cdot 0$ \\
\hline
\end{tabular}

other cokeworkers the prevalence in the dusty group was $20.1 \%$ compared with $11.3 \%$ in the non-dusty group.

In order to ensure that these findings were not simply due to age differences in the various occupational groups, comparisons were made of the prevalence of bronchitis within individual 10-year age groups (Table available on request to authors). Although this could not be done for the under 25 years age group owing to lack of numbers, it was concluded that the trends observed in Table 2 were not due to age differences in the main subgroups.

The possibility that the results might have been affected by differences in smoking habits was then investigated. In view of the relatively small numbers and as the proportion of dusty/non-dusty men who smoked was similar in both the ovensmen and the other cokeworkers' groups, bronchitis levels in all ovensmen were compared-to-those in all other cokeworkers. It was found that the prevalence of bronchitis among all the ovensmen who smoked cigarettes was $31.7 \%$ compared with $23.0 \%$ among all the other cokeworkers who smoked (Table 3), a difference of $8.7 \%(P<0.02)$. When non-smokers were considered the difference in bronchitis prevalence between all the ovensmen $(8.8 \%)$ and all the other cokeworkers $(6.0 \%)$ was much less but this may be due to the higher proportion of dusty men in the other cokeworkers' group. Ideally, any occupational group effect would best be determined by comparing only the non-dusty, non-smoking ovensmen with their counterparts who worked elsewhere in the cokeworks, and although the former group had more than twice as much bronchitis as the latter group $(11.1 \%$ compared with $5.3 \%)$ the numbers involved were too small to be significant.

When the effect of previous occupation was examined among cigarette smokers, the prevalence of bronchitis among all the dusty men was $8.3 \%$ higher than among the non-dusty men $(29.6 \%$ compared with $21.3 \%, P<0 \cdot 1)$. It was considered that ovensmen and other cokeworkers could be combined as the proportion of ovensmen in the dusty and nondusty groups was similar. That there was no such difference among the non-smokers $(6.6 \%$ for the dusty group compared with $\mathbf{7 . 8 \%}$ for the non-dusty group) may be due to the higher proportion of ovensmen in the non-dusty, non-smoking group. Lack of numbers prevented a direct comparison between the dusty and non-dusty men in the nonsmoking other cokeworkers' group where any effect of past occupation would be best seen.

TABLE 3

Effect of Cigarette Smoking, Occupational Group, and Previous Industrial History on Prevalence OF BRONCHITIS IN MEN OVER 25 YeARS

\begin{tabular}{|c|c|c|c|c|c|c|c|c|c|}
\hline & & & & \multicolumn{2}{|c|}{ Ovensmen } & \multicolumn{2}{|c|}{ Other cokeworkers } & \multicolumn{2}{|c|}{ Total } \\
\hline & & & & Smokers & Non-smokers & Smokers & Non-smokers & Smokers & Non-smokers \\
\hline $\begin{array}{l}\text { Dusty history .. } \\
\text { Non-dusty history }\end{array}$ & $\begin{array}{l}\cdots \\
\cdots\end{array}$ & $\begin{array}{l}\cdots \\
\cdots\end{array}$ & $\begin{array}{l}\cdots \\
\cdots\end{array}$ & $\begin{array}{c}35.3 \% \\
(139) \\
25.6 \% \\
(82)\end{array}$ & $\begin{array}{c}6.5 \% \\
(46) \\
11 \cdot 1 \% \\
(45)\end{array}$ & $\begin{array}{c}25 \cdot 7 \% \\
(202) \\
18 \cdot 6 \% \\
(129)\end{array}$ & $\begin{array}{c}6.6 \% \\
(76) \\
5 \cdot 3 \% \\
(57)\end{array}$ & $\begin{array}{c}29 \cdot 6 \% \\
(341) \\
21 \cdot 3 \% \\
(211)\end{array}$ & $\begin{array}{l}6.6 \% \\
(122) \\
7.8 \% \\
(102)\end{array}$ \\
\hline Total $\ldots$ & . & .. & .. & $\begin{array}{c}31 \cdot 7 \% \\
(221)\end{array}$ & $\begin{array}{l}8.8 \% \\
(91)\end{array}$ & $\begin{array}{c}23.0 \% \\
(331)\end{array}$ & $\begin{array}{l}6.0 \% \\
(133)\end{array}$ & $\begin{array}{c}26.4 \% \\
(552)\end{array}$ & $\begin{array}{l}7 \cdot 1 \% \\
(224)\end{array}$ \\
\hline
\end{tabular}

The figures in parentheses were the number of men on whom the percentage was based. 
Smoking The prevalence of bronchitis among cigarette smokers was very much higher than among non-smokers $(25.2 \%$ compared with $6.6 \%$, Table 4$)$ although there did not appear to be a close relationship between bronchitis prevalence and the number of cigarettes smoked (Table 5).

TABLE 4

SMoking Habits and Bronchitis (All Workers)

\begin{tabular}{|c|c|c|c|c|}
\hline & \multirow{2}{*}{$\begin{array}{c}\text { Average } \\
\text { age }\end{array}$} & \multirow{2}{*}{$\begin{array}{c}\text { No. of } \\
\text { men }\end{array}$} & \multicolumn{2}{|c|}{ Bronchitis } \\
\hline & & & No. & $\%$ \\
\hline $\begin{array}{l}\text { Non and ex-smokers } \\
\text { Pipe smokers } \quad . \\
\text { Cigarette smokers .. }\end{array}$ & $\begin{array}{l}45 \cdot 4 \\
49 \cdot 7 \\
44 \cdot 0\end{array}$ & $\begin{array}{r}242 \\
52 \\
587\end{array}$ & $\begin{array}{r}16 \\
5 \\
148\end{array}$ & $\begin{array}{r}6 \cdot 6 \\
9 \cdot 6 \\
25 \cdot 2\end{array}$ \\
\hline . $\quad \ldots$ & & 881 & 169 & $19 \cdot 2$ \\
\hline
\end{tabular}

TABLE 5

Bronchitis in Cigarette SMokers

\begin{tabular}{lll|c|c|c|c}
\hline \multicolumn{2}{c|}{$\begin{array}{c}\text { No. of cigarettes } \\
\text { smoked per day }\end{array}$} & $\begin{array}{c}\text { Average } \\
\text { age }\end{array}$ & $\begin{array}{c}\text { No. of } \\
\text { men } \\
\text { in group }\end{array}$ & \multicolumn{2}{|c}{ Bronchitis } \\
\cline { 5 - 7 } & & No. & $\%$ \\
\hline $1-10$ &. &. & $44 \cdot 0$ & 150 & 40 & $26 \cdot 7$ \\
$11-20$ &. &. & $44 \cdot 2$ & 290 & 66 & $22 \cdot 8$ \\
$20+$ &. &. & $43 \cdot 8$ & 147 & 42 & $28 \cdot 6$ \\
\hline Total &. &. & & 587 & 148 & $25 \cdot 2$ \\
\hline
\end{tabular}

The difference in the prevalence of bronchitis in men over the age of 25 years (Table 6) between cigarette smokers $(26.4 \%)$ and non-smokers $(7 \cdot 1 \%)$ was $19.3 \%(\mathrm{P}<0.001)$.

Effect of various environmental and physical factors on ventilatory capacity

The independent effect on ventilatory capacity of four factors considered to be of special interest was investigated. These factors were: bronchitis, occupa-

TABLE 6

Smoking Habits and Bronchitis in All Workers (OVER 25 Years OF AGE)

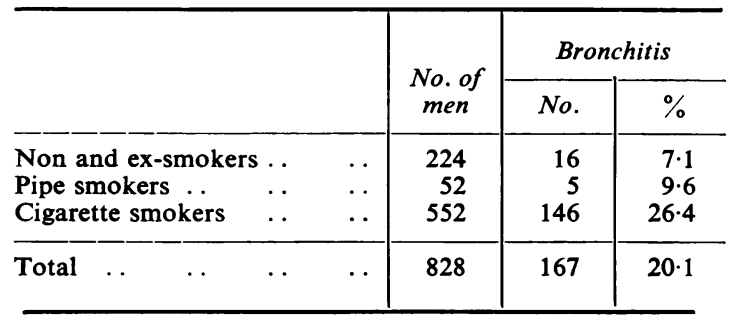

tional group, previous employment in a dusty industry, and smoking.

The cokeworkers were classified into 16 subgroups corresponding to all the combinations of the four factors. Men under 25 years of age were excluded from the analysis because ventilatory capacity normally increases with age until a peak is reached between the ages of 21 and 25 years after which it declines with age. Like Ashford, Brown, Morgan, and Rae (1968), we found that the variables affecting ventilatory capacity were, in order of importance, age, height, sitting height, and weight, but in this case as the effects of the last two were frequently nonsignificant only age and height were included in the final analysis.

It was found that an increase in age was associated with a drop in $\mathrm{FEV}_{1}$ of 0.04 1./year, while an increase in height resulted in an improvement in $\mathrm{FEV}_{1}$ by the same amount per centimetre.

The mean $\mathrm{FEV}_{1}$ values in the 16 subgroups before and after adjustment to the same age and height are shown in Table 7. By comparing these adjusted mean $\mathrm{FEV}_{1}$ levels in the various subgroups, the effects of the four factors which might possibly affect ventilatory capacity can be examined although it should be emphasized that the numbers of men in some of the subgroups were very small.

It was found that the effect of these factors was as follows:

(a) Bronchitis: With the exception of one subgroup, men with bronchitis had lower $\mathrm{FEV}_{1}$ levels than their counterparts with no bronchitis.

(b) Occupational group: In each subgroup ovensmen had lower $\mathrm{FEV}_{1}$ levels than other cokeworkers (in one instance the levels were identical).

(c) Previous employment in a dusty industry: Among cigarette smokers the $\mathrm{FEV}_{1}$ levels of dusty men were lower than those found in non-dusty men. The reverse was generally true in the case of non and ex-smokers.

(d) Smoking: In half the subgroups smokers had a lower mean $\mathrm{FEV}_{1}$ than non-smokers.

The overall significance of these findings was investigated using an analysis of co-variance. This showed that the most important factor was bronchitis which was associated with a drop in mean FEV $_{1}$ of 0.16 litres $(P<0.001)$. The next factor of importance was occupational group, which, in ovensmen was associated with a drop in mean FEV $_{1}$ of 0.05 litres $(P<0.01)$. Smoking and previous employment in a dusty industry had only a small effect on ventilatory capacity when taken by themselves, but in combination they were associated with a drop in mean $\mathrm{FEV}_{1}$ of 0.08 litres $(\mathrm{P}<0.05)$.

\section{Discussion}

The results indicated that in the sample of cokeworks population examined, the prevalence of 
TABLE 7

FEV Levels in Men over 25 Years by Bronchitis State, Smoking Habits, Previous Industrial EXPERIENCE, AND OCCUPATIONAL GROUP

\begin{tabular}{|c|c|c|c|c|c|c|c|c|}
\hline \multirow{3}{*}{$\frac{\text { Previous occupation }}{\text { Present occupation }}$} & \multicolumn{4}{|c|}{ Smokers } & \multicolumn{4}{|c|}{ Non-smokers and ex-smokers } \\
\hline & \multicolumn{2}{|c|}{ Dusty } & \multicolumn{2}{|c|}{ Non-dusty } & \multicolumn{2}{|c|}{ Dusty } & \multicolumn{2}{|c|}{ Non-dusty } \\
\hline & Ovensmen & Others & Ovensmen & Others & Ovensmen & Others & Ovensmen & Others \\
\hline $\begin{array}{l}\text { Bronchitis group } \\
\text { No. of men } \\
\text { Mean age }(\mathrm{yr}) \\
\text { Mean height (cm) }\end{array}$ & $\begin{array}{c}49 \\
48 \cdot 0 \\
171 \cdot 5 \\
2 \cdot 66 \\
2 \cdot 72\end{array}$ & $\begin{array}{c}52 \\
50 \cdot 6 \\
171.6 \\
2.74 \\
2.91\end{array}$ & $\begin{array}{c}21 \\
45 \cdot 6 \\
171 \cdot 9 \\
2 \cdot 89 \\
2 \cdot 83\end{array}$ & $\begin{array}{c}24 \\
49 \cdot 6 \\
172 \cdot 0 \\
2 \cdot 81 \\
2 \cdot 91\end{array}$ & $\begin{array}{c}3 \\
59 \cdot 0 \\
168 \cdot 0 \\
1 \cdot 82 \\
2 \cdot 48\end{array}$ & $\begin{array}{c}5 \\
56 \cdot 4 \\
168 \cdot 4 \\
2 \cdot 87 \\
3 \cdot 40\end{array}$ & $\begin{array}{c}5 \\
53 \cdot 2 \\
167 \cdot 0 \\
2 \cdot 28 \\
2 \cdot 74\end{array}$ & $\begin{array}{c}3 \\
47 \cdot 3 \\
171 \cdot 7 \\
3 \cdot 13 \\
3 \cdot 15\end{array}$ \\
\hline 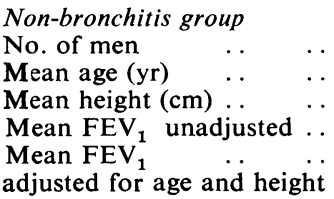 & $\begin{array}{c}90 \\
44 \cdot 5 \\
171 \cdot 4 \\
3 \cdot 17 \\
3.09\end{array}$ & $\begin{array}{c}150 \\
45 \cdot 3 \\
170 \cdot 7 \\
3 \cdot 22 \\
3 \cdot 20\end{array}$ & $\begin{array}{c}61 \\
43 \cdot 5 \\
172 \cdot 7 \\
3 \cdot 35 \\
3 \cdot 18\end{array}$ & $\begin{array}{c}105 \\
43 \cdot 1 \\
170 \cdot 9 \\
3 \cdot 36 \\
3 \cdot 25\end{array}$ & $\begin{array}{c}43 \\
48 \cdot 3 \\
170 \cdot 8 \\
3 \cdot 22 \\
3 \cdot 33\end{array}$ & $\begin{array}{c}71 \\
49 \cdot 5 \\
171 \cdot 7 \\
3 \cdot 21 \\
3 \cdot 33\end{array}$ & $\begin{array}{c}40 \\
44 \cdot 9 \\
171 \cdot 8 \\
3 \cdot 22 \\
3 \cdot 14\end{array}$ & $\begin{array}{r}54 \\
43 \cdot 6 \\
171 \cdot 7 \\
3 \cdot 37 \\
3 \cdot 24\end{array}$ \\
\hline
\end{tabular}

bronchitis was very closely related to cigarette smoking $(\mathbf{P}<0.001)$ although no clear relationship was observed between prevalence and the actual amount smoked. This latter finding could have been accounted for by the difference in age and/or the proportion of dusty men and ovensmen in the different smoking categories but investigation of these possibilities (not reported here) revealed that this was not the case. Smoking has also been considered to be a major contributing factor in the development of respiratory symptoms in British coalminers by Ashford, Morgan, Rae, and Sowden (1970).

A higher prevalence of bronchitis was found in men working in the environment of the coke-ovens compared with men who worked elsewhere in the cokeworks $(P<0.02)$. That this was true only for cigarette smokers suggests that it may be a combination of the environment of the ovens and cigarette smoking that is responsible for the higher prevalence of bronchitis in ovensmen. An alternative explanation is that the smoking classification has been too imprecise and that ovensmen as a group smoked more cigarettes than the other cokeworkers. However, even if this were so, it was found in this study (Table 5) that there was not a close relationship between symptoms of bronchitis and the amount smoked. The first possibility is supported by the work of Sluis-Cremer and his colleagues (1967) who carried out an investigation on chronic bronchitis in miners and non-miners in a goldmining area in the Transvaal. They found that only those miners who smoked had significantly more bronchitis than nonminers and they suggested that this was due to an interaction of smoking and underground aerial pollution.

Among cigarette smokers, men who had previously been employed in a dusty occupation were found to have more bronchitis (Table 3) and a reduced ventilatory capacity (Table 7) compared with their colleagues with no such past occupational history. This is perhaps not surprising in view of the presence in the dusty group of a large number of ex-coalminers who are known to have more respiratory symptoms and a lower ventilatory capacity than men who have worked only in dust-free occupations (Higgins et al., 1959). It is unlikely, however, that the excess of bronchitis among ovensmen who smoked (Table 3) is due to the presence in that group of a large number of ex-coalminers, as the proportion of ex-miners among ovensmen and other cokeworkers is almost identical. The association between previous employment in a dusty occupation and symptoms of bronchitis and lowered ventilatory capacity is observed only in cigarette smokers. This suggests an aetiological combination of smoking and atmospheric pollution at the place of work.

The effect of various environmental and physical factors on ventilatory capacity was considered, and, after standardizing for age and height, the independent effect on $\mathrm{FEV}_{1}$ of bronchitis state, occupational group, previous occupation, and smoking habits was examined. Of these, the presence of bronchitis was found to be the most significant factor $(P<0.001)$. Employment in the occupational group of ovensmen was also important $(P<0.01)$ but whether this was due to a direct non-bronchitic effect of the ovens environment on the lungs or to ovensmen possibly 
suffering from subclinical bronchitis, it is difficult to say. It is interesting to note that Higgins and his coworkers (1959) also found a reduction in ventilatory capacity among coke-oven workers, although the number of men examined was very small. The effect of cigarette smoking on $\mathrm{FEV}_{1}$ was, contrary to expectation, small but this may be due to the inclusion in the statistical analysis of ex-smokers in the non-smoking group. The effect of previous employment in a dusty occupation has already been referred to above.

The investigation suggests that cigarette smoking, both by itself and in combination with pollution from the coke-ovens and previous occupation, are important factors in the aetiology of bronchitis and reduced ventilatory capacity in the sample of the cokeworks population studied. It is possible that the environmental hazard may have been underestimated by including in the ovensmen group men who were very much less exposed to pollution than others who worked on top of the ovens.

As in all epidemiological studies based on working populations, the results are subject to the effect of population selection and a comparative lack of numbers in some of the subgroups examined. It may be, too, that the sample of the cokeworkers was not representative of the industry although the similarity of the results from the two cokeworks where the investigation took place suggests this is unlikely. It is possible that the differences in bronchitis levels between ovensmen and the 'other cokeworkers' might be due to social class. However, as clerical staff were not included in the 'other cokeworkers' group this explanation is unlikely and would not explain the differences observed in ventilatory capacity.

Of the possible actions which can be taken to reduce the prevalence of bronchitis, encouragement to stop smoking is likely to be the most effective although the success of antismoking campaigns tends to be very limited. Several measures can be taken to reduce the emission of fumes from the cokeovens while the wearing of respirators by men employed as ovensmen might be beneficial.

Further work is necessary to identify the exact nature of the environmental hazard.

A note on the statistical method used to investigate the significance of factors affecting ventilatory capacity is available on request to the authors.

The encouragement of the Chief Medical Officer, Dr. J. M. Rogan, and the assistance and helpful advice of Dr. S. Rae are gratefully acknowledged.

\section{References}

Ashford, J. R., Brown, Susannah, Morgan, D. C., and Rae. S. (1968). The pulmonary ventilatory function of coal miners in the United Kingdom. Amer. Rev. resp. Dis., 97, 810-826.

_-, Morgan, D. C., Rae, S., and Sowden, R. R. (1970). Respiratory symptoms in British coalminers. Amer. Rev. resp. Dis., 102, 370-381.

Daly, C. (1959). Air pollution and causes of death. Brit. J. prev. soc. Med., 13, 14-27.

Doll, R., and Hill, A. B. (1956). Lung cancer and other causes of death in relation to smoking: a second report on the mortality of British doctors. Brit. med.J., 2, 10711081.

Higgins, I.T.T., Cochrane, A. L., Gilson, J. C., and Wood, C.H. (1959). Population studies of chronic respiratory disease. A comparison of miners, foundryworkers and others in Staveley, Derbyshire. Brit. J. industr. Med., 16, 255-268. - Oldham, P. D., Cochrane, A. L., and Gilson, J. C. (1956). Respiratory symptoms and pulmonary disability in an industrial town. Brit. med. J., 2, 904-910.

Kandus, J. (1968). Vliv Ekologickych Cinitelu na Incidenci Chronicke Bronchitidy u Horniku Ostravsko-Karvinskeho Reviru. Rozhl. Tuberk., 28, 394-401.

Lawther, P. J. (1967). Air pollution and chronic bronchitis. Med. Thorac., 24, 44-52.

Lowe, C. R. (1968). Chronic bronchitis and occupation. Proc. roy. Soc. Med., 61, 98-102.

Medical Research Council (1966). Chronic bronchitis and occupation. Brit. med. J., 1, 101-102.

Pemberton, J. (1968). Occupational factors in chronic bronchitis. Proc. roy. Soc. Med., 61, 95-98.

- - , and Goldberg, C. (1954). Air pollution and bronchitis. Brit. med. J., 2, 567-570.

Reid, D. D. (1964). Air pollution as a cause of chronic bronchitis. Proc. roy. Soc. Med., 57, 965-968.

Royal College of Physicians of London (1962). Smoking and Health, p. 28. Pitman Medical Publishing Co., London.

Sluis-Cremer, G. K., Walters, L. G., and Sichel, H. S. (1967). Chronic bronchitis in miners and non-miners: an epidemiological survey of a community in the goldmining area in the Transvaal. Brit. J. industr. Med., 24, 1-12.

Stocks, P. (1959). Cancer and bronchitis mortality in relation to atmospheric deposit and smoke. Brit. med. J., 1, 74-79.

U.S. Public Health Service (1964). Smoking and Health. Report of the Advisory Committee to the Surgeongeneral. Publ. Hlth Service Publication No. 1103. U.S. Government Printing Office, Washington.

\section{Appendix I}

List of jobs classified in the ovensmen group

1. Coke car man

2. Coke guide man

3. Doorman

4. Heaterman

5. Larry car man and lid man

6. Ram man

7. Valve man

8. Patcher

9. Foreman heater

10. Tradesman (specifically employed on 'ovens')

Received for publication June 30, 1970. 